\title{
REVIEW
}

\section{Salt of the earth or a drop in the ocean? A pathophysiological approach to fluid resuscitation}

\section{P Gosling}

The evolved endocrine response after injury leads to sodium, chloride, and water retention at a time when large volumes of sodium containing fluids are given to maintain the circulation and preserve tissue oxygenation. Sodium, chloride, and water are also retained because of increased systemic vascular permeability to plasma proteins, especially albumin, which sequesters fluid in the interstitial space and causes oedema. Excessive fluid and electrolyte retention and interstitial oedema are associated with the systemic inflammatory response syndrome and multiple organ dysfunction, and failure. This review attempts an overview of these processes and addresses the question, "Can manipulation of fluid resuscitation influence the inflammatory response to injury and organ function". Results of randomised controlled prospective clinical studies suggest that limiting the sodium and chloride input and optimal use of synthetic colloids, which are well retained in the vascular space, can reduce the inflammatory response to injury and improve organ function.
Correspondence to: Dr P Gosling, Clinical Biochemistry Department Selly Oak Hospital University Hospital Birmingham NHS Trust Raddlebarn Road, Birmingham B29 6LD, UK; Peter.Gosling@uhb.nhs.uk
$T$ he extracellular fluid composition of human beings reflects that of the primordial sea when life emerged millions of years ago. Homeostatic mechanisms have evolved to maintain the extracellular environment within very tight limits. In response to the renin-angiotensinaldosterone system, brain and atrial natriuretic hormones, and the posterior pituitaryvasopressin-renal axis, the kidneys maintain extracellular fluid sodium and tonicity, and contribute to the maintenance of blood pressure. After perturbations such as haemorrhage, blunt trauma, burns, infection, starvation, and dehydration, these same evolutionary processes have also led to a response that is directed towards maintenance of the extracellular environment.

In injured or acutely ill patients, fluid therapy aimed at preserving oxygen delivery to the tissues is superimposed upon a powerful homeostatic response. This review aims to describe this response and place in context recent studies of the effects of different fluid resuscitation regimens on the inflammatory process and organ function. There is still no consensus on which fluid regimen is optimal for acute volume replacement after surgical or traumatic insult, and attempts at mortality based meta-analysis to answer this question have been unsuccessful. ${ }^{12}$ The data reviewed here suggest that an approach based on prospective controlled clinical studies that monitor the pathophysiological response and organ function may be more informative and provide an evidence base for optimising fluid therapy in acutely ill patients.

\section{SODIUM AND WATER HOMEOSTASIS AFTER INJURY}

The stress response after insults such as surgery, trauma, haemorrhage, burns, or cardiopulmonary arrest leads to water and sodium conservation and selective vasoconstriction preserving the blood supply to the brain, heart, and lungs. These mechanisms are summarised in figure 1.

An adult's sodium intake varies greatly with their diet, but is typically between 100 and 220 $\mathrm{mmol} / 24 \mathrm{~h},{ }^{3}$ accompanied by about 1.5 to 2.5 litres of water. Despite the wide range of salt and water intake, the kidneys maintain the extracellular fluid sodium concentration within a narrow range, mediated by vasopressin, the renin-angiotensinaldosterone system and brain and atrial natiuretic peptides.

In contrast a patient admitted after major trauma will receive far more sodium and water. Blood loss and inflammation induced systemic capillary leak, (see later) will tend to make the patient hypovolaemic. In addition anaesthetic agents used for corrective surgery will reduce systemic vascular resistance and will also tend to make the patient hypovolaemic. These effects are countered by the intravenous administration of red blood cells and fluids, the water and salt content of the fluid being several times the normal daily intake.

The 24 hour fluid input for a patient undergoing resuscitation for major trauma is presented in table 1. Such a patient will have mounted a stress response with increased secretion of vasopressin, renin, angiotensin II, aldosterone, and decrease in natiuretic peptide release. Thus in addition to the fluid and sodium that have been given to fill the depleted vascular compartment and replace traumatic blood losses and any intraoperative losses, the patient will be conserving water and sodium intensely. The first 24 hour urine output was 1000 $\mathrm{ml}$ and the sodium excretion was $50 \mathrm{mmol}$. Based on $5000 \mathrm{ml}$ blood loss and $800 \mathrm{ml}$ insensible losses, this leaves the patient at the end of their first 24 hours in positive fluid balance by about $8800 \mathrm{ml}$ and a positive sodium balance of about $1500 \mathrm{mmol}$. While these figures may seem excessive, a review of postoperative fluid and electrolyte prescribing revealed that patients may receive around $7000 \mathrm{ml}$ of water and $700 \mathrm{mmol}$ of sodium and chloride in 


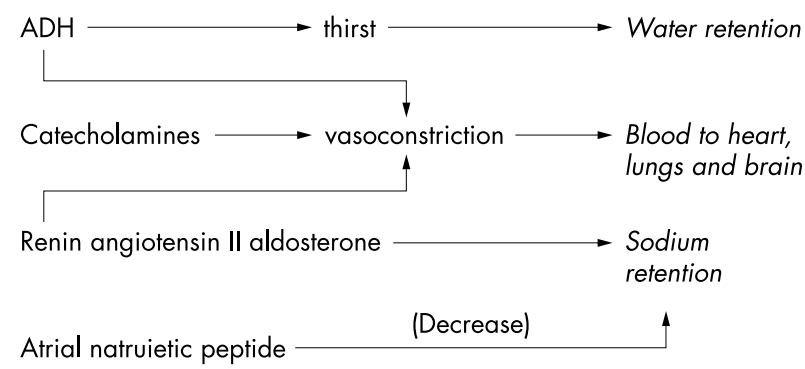

Figure 1 Summary of the endocrine responses to acute injury, which are directed towards maintaining perfusion of essential organs and retention of water and sodium.

the first postoperative day. ${ }^{4}$ What happens next is critical to the patient's subsequent course. This is illustrated by two contrasting case studies of major trauma. The fluid and sodium balance corrected for insensible losses are presented in figures $2-5$.

Patient A (fig 2) responded rapidly to fluid resuscitation and began off loading their resuscitation fluid load by day 4 , and was close to zero balance by day 5 . The $\mathrm{pO}_{2} / \mathrm{FiO}_{2}$ ratio above 40 kpa indicates that lung function was well maintained, and the patient was breathing air by day 10 and left the ICU on day 12 . Despite receiving over $1100 \mathrm{mmol}$ of sodium over the first three days, the patient's cumulative sodium balance was close to zero by day 6 ( fig 3 ).

In contrast, patient B (fig 4 and 5) required large volumes of colloids and crystalloids to maintain cardiovascular parameters within acceptable limits, and the $\mathrm{pO}_{2} / \mathrm{FiO}_{2}$ ratio was persistently low. There was profound water retention, which was maximum by day 8 , at which point the $\mathrm{pO}_{2} / \mathrm{FiO}_{2}$ ratio was at its lowest and the patient had developed acute respiratory distress syndrome (ARDS) (fig 4). Diuretics were started and there was a gradual improvement in lung function, which was accompanied by mobilisation of sodium and water. On day 15 the patient became septic, with a fall in $\mathrm{pO}_{2} / \mathrm{FiO}_{2}$ ratio and subsequent recurrent fluid retention. Unlike patient A, sodium balance closely followed fluid balance for the first 13

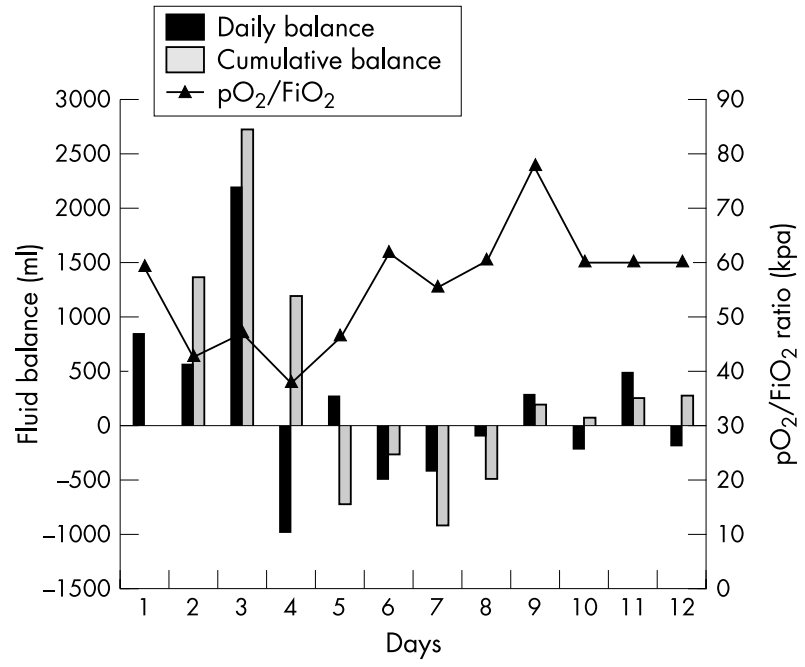

Figure 2 Case A: fluid balance and $\mathrm{pO}_{2} / \mathrm{FiO}_{2}$ ratio for a patient making an uncomplicated recovery from major trauma. The normal $\mathrm{pO}_{2} / \mathrm{FiO}_{2}$ ratio is about $60 \mathrm{kpa}$. (See text for interpretation).

days, with maximum sodium loading by day 8 , and a progressive natriuesis until day 15, and a minor episode of sodium retention associated with sepsis (fig 5 ).

Excreting water and sodium is further compromised in patients with a major catabolic response to surgery, trauma, or sepsis. Returning to patient B, figure 6 shows the serum C reactive protein (a general marker of inflammation) and urine urea excretion. There was a post-trauma rise in serum $\mathrm{C}$ reactive protein, with further increases associated with ARDS (days 9-14) and sepsis (days 15-19). Each period of inflammation was accompanied by increased urine urea nitrogen excretion. Figure 7 shows the calculated urine osmolality, (a rough approximation derived from doubling the sum of the sodium and potassium excretion and adding the urea excretion) and illustrates the solute load the kidneys were excreting. Urinary urea was an important contributor to the urine osmolality during this period, and during each

\begin{tabular}{|c|c|c|c|c|c|}
\hline \multirow[b]{2}{*}{ Fluid } & \multirow[b]{2}{*}{ Volume $\mathrm{ml}$} & \multicolumn{2}{|c|}{ Content $\mathrm{mmol} / \mathrm{l}$} & \multicolumn{2}{|c|}{$\mathrm{NaCl}$ load mmol/24 h } \\
\hline & & $\mathrm{Na}$ & $\mathrm{Cl}$ & $\mathrm{Na}$ & $\mathrm{Cl}$ \\
\hline \multicolumn{6}{|l|}{ Input } \\
\hline \multicolumn{6}{|l|}{ In A\&E } \\
\hline $0.9 \%$ Saline & 2000 & 150 & 150 & 300 & 300 \\
\hline Gelatine & 2000 & 150 & 150 & 300 & 300 \\
\hline \multicolumn{6}{|l|}{ In theatre } \\
\hline $0.9 \%$ Saline & 2000 & 150 & 150 & 300 & 300 \\
\hline Gelatine & 1000 & 150 & 150 & 150 & 150 \\
\hline \multicolumn{6}{|l|}{$\ln \mathrm{ICU}$} \\
\hline $0.9 \%$ Saline & 3000 & 150 & 150 & 450 & 450 \\
\hline Gelatine & 1500 & 150 & 150 & 225 & 225 \\
\hline Frozen plasma & 1250 & 140 & 95 & 175 & 119 \\
\hline Nasogastric feed & 600 & 70 & 70 & 42 & - \\
\hline $24 \mathrm{~h}$ totals & 13350 & & & 1942 & 1844 \\
\hline \multicolumn{6}{|l|}{ Output } \\
\hline $\begin{array}{l}\text { Plasma loss* } \\
\text { Insensible loss }\end{array}$ & $\begin{array}{l}2750 \\
800\end{array}$ & 140 & 95 & 385 & 261 \\
\hline Urine & 1000 & 50 & 50 & 50 & 50 \\
\hline $24 \mathrm{~h}$ totals & 4550 & & & 435 & 311 \\
\hline Balance & +8800 & & & +1507 & +1533 \\
\hline
\end{tabular}

*Plasma loss based on an estimated blood loss of $5000 \mathrm{ml}$ and packed cell volume of 0.45 $(5000 \times 0.55=2750 \mathrm{ml}$ plasma loss). 


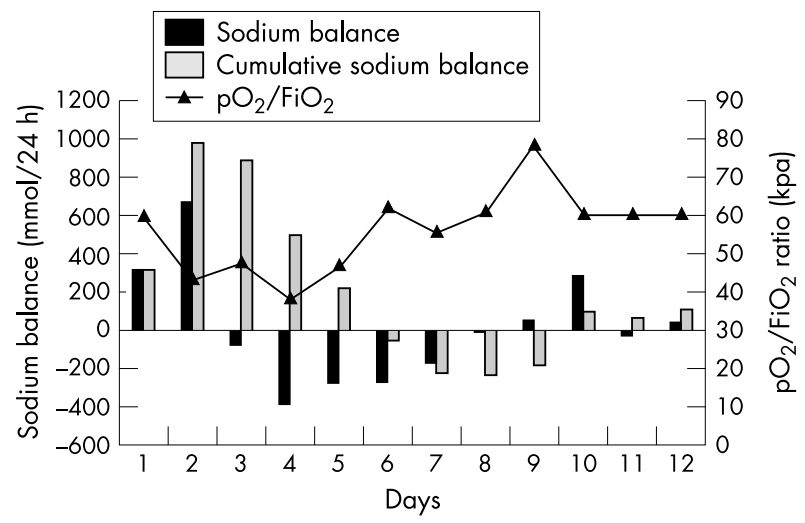

Figure 3 Case $\mathrm{A}$ : sodium balance and $\mathrm{pO}_{2} / \mathrm{FiO}_{2}$ ratio for a patient making an uncomplicated recovery from major trauma. The normal $\mathrm{pO}_{2} / \mathrm{FiO}_{2}$ ratio is about $60 \mathrm{kpa}$. (See text for interpretation).

inflammatory episode, the osmotic load to be excreted increased and was accompanied by hypernatraemia. This was because patient B's sodium excretion had to compete with their need to excrete nitrogen, and hypernatraemia developed during the periods of greatest urine nitrogen excretion (fig 7). Even in a fit person, the maximum achievable urine concentration is about $1000 \mathrm{mosmol} / \mathrm{l}$, and in critically ill patients it is frequently half this value. ${ }^{5}$ If the free water input is insufficient, then both hypernatraemia and uraemia will result, and attempts to mobilise oedema will be thwarted by the hyperosmolar state stimulating vasopressin release and encouraging fluid retention. The logical treatment of oedema under these circumstances is to increase the urine volume by increasing free water input with addition of a diuretic if necessary to override the effects of vasopressin. If this fails haemofiltration may be required.

Hyponatraemia in acutely ill patients who have received intravenous fluids is also common. Unfortunately this is sometimes interpreted as an indication for giving more sodium, yet the cause of hyponatraemia is hardly ever sodium deficiency. Usually such patients have a high whole body sodium content, especially if they have a positive fluid balance. Serum sodium and potassium concentrations are very poor indicators of their whole body status

There are a number of possible explanations for hyponatraemia with whole body sodium excess, which include accumulation of fluid in the expanded interstitial space due to

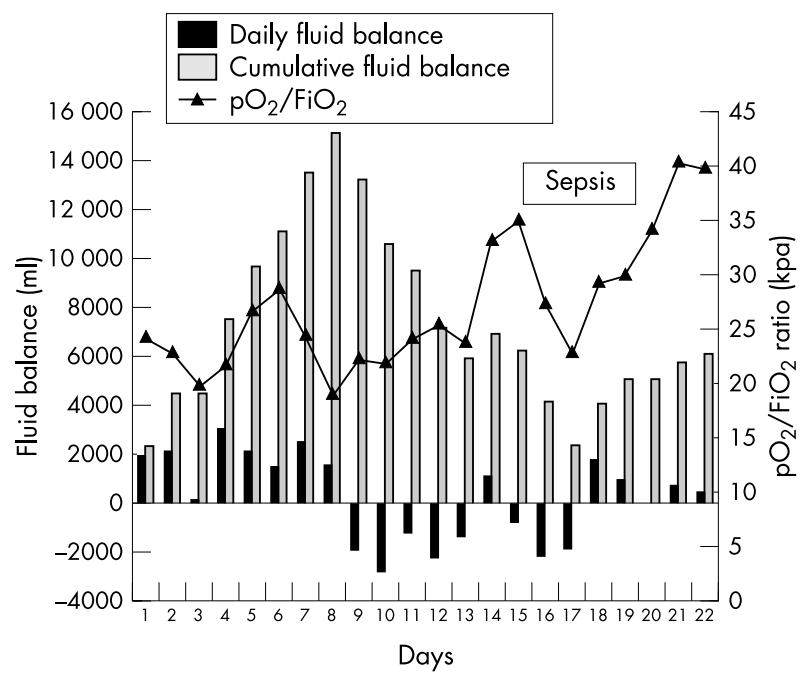

Figure 4 Case $\mathrm{B}$ : fluid balance and $\mathrm{pO}_{2} / \mathrm{FiO}_{2}$ ratio, for a patient suffering post-trauma ARDS and later sepsis.

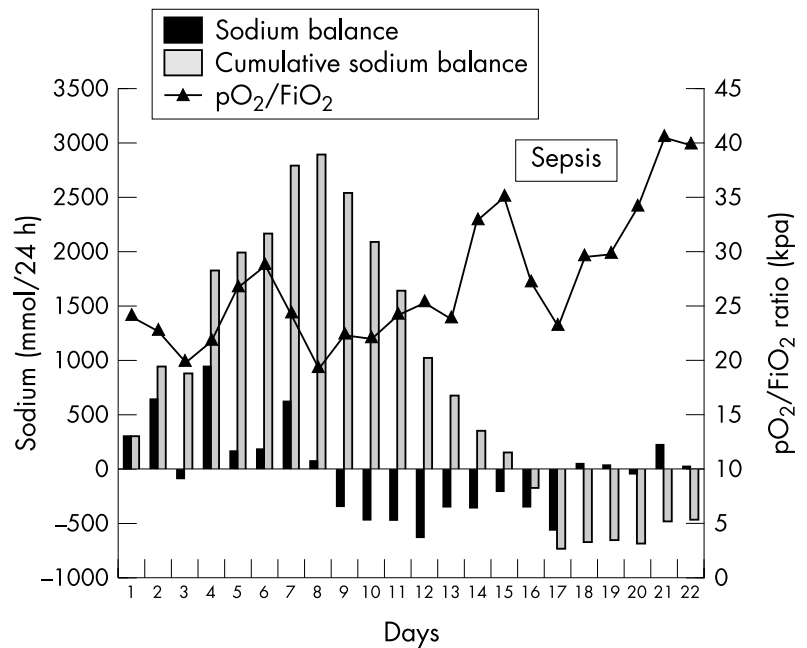

Figure 5 Case $\mathrm{B}$ : sodium balance and $\mathrm{pO}_{2} / \mathrm{FiO}_{2}$ ratio, for a patient suffering post-trauma ARDS and later sepsis. The normal $\mathrm{pO}_{2} / \mathrm{FiO}_{2}$ ratio is about $60 \mathrm{kpa}$. (See text for interpretation).

translocation of albumin and fluid through leaky capillaries, and water retention due to stress related release of vasopressin. Sodium is also lost from the extracellular space into the cells. The "sick cell syndrome" theory for explaining chronic hyponatraemia, suggests movement of sodium into the cells occurs due to "loss of intracellular solute" and that there is no cellular oedema. ${ }^{6}$ However there is evidence from clinical and animal studies that acute injury and inflammation lead to intracellular sequestration of sodium, chloride, and water, and may cause cellular oedema. Cunningham and Shires ${ }^{7}$ demonstrated a more than doubling of red cell sodium and fall in red cell potassium after shock of long duration in 25 patients. In a typical case, red cell sodium concentration rose by $12 \mathrm{mmol} / \mathrm{l}$ within five hours of the onset of shock, and rapidly returned to normal after surgery to repair a lacerated mesenteric artery. The authors suggested that deficiency of intracellular energy (ATP) may lead to reduction in the activity of the cellular sodium potassium pump, allowing sodium to enter the cells. In addition to a cellular energy deficit attributable to hypoxia, prolonged release of nitric oxide in severe inflammation, irreversibly inhibits mitochondrial complex IV function, further depleting supplies of ATP. ${ }^{8}$ There are numerous animal studies showing changes in cellular sodium potassium pump activity in response to various interventions. Hannon and Boston" observed a shift of sodium, chloride, and water into skeletal muscle cells within 12 hours of caecal ligation and puncture in rats.

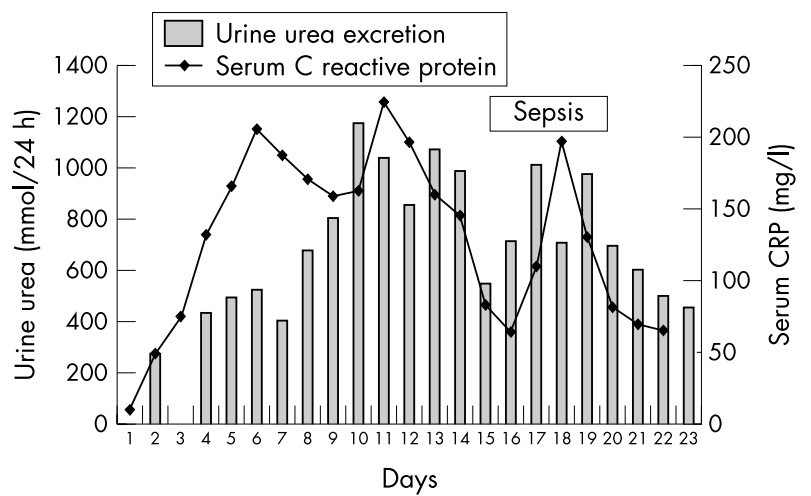

Figure 6 Case $B$ : urinary urea excretion and serum $C$ reactive protein for a patient suffering ARDS and later sepsis after major trauma. Normal urine urea excretion is $250-500 \mathrm{mmol} / 24 \mathrm{~h}$, and serum $\mathrm{C}$ reactive protein $<10 \mathrm{mg} / \mathrm{l}$. (See text for interpretation). 


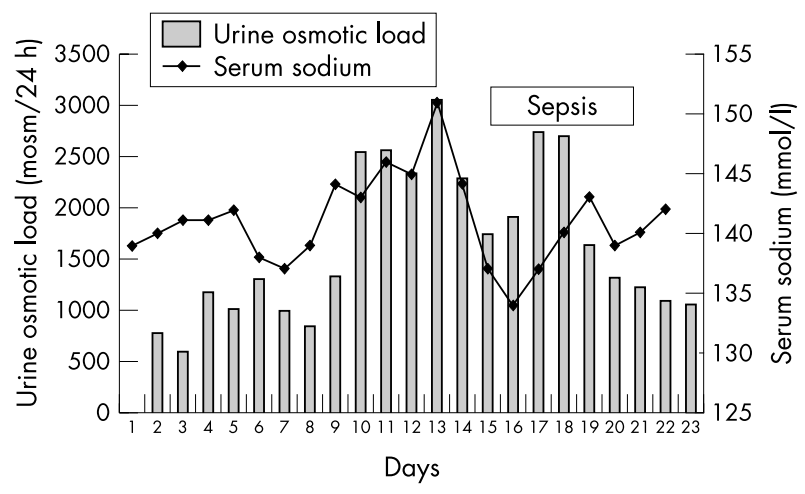

Figure 7 Case $B$ : urine osmotic load and serum sodium concentration for a patient suffering ARDS and later sepsis after major trauma. (See text for interpretation).

Patient B probably suffered intracellular sodium accumulation. On day 8 the patient was in positive fluid balance of 15 litres (fig 4) with a positive sodium balance of $2900 \mathrm{mmol}$ (fig 5 ). The extracellular sodium concentration was $138 \mathrm{mmol} / \mathrm{l}$ (fig 7). The sodium content of the additional 15 litres can be calculated $(138 \times 15)$ and comes to $2070 \mathrm{mmol}$, leaving a positive sodium balance of $830 \mathrm{mmol}$ of sodium that cannot be accounted for. Attempting to assess accurately sodium balance is very difficult, but assuming there are no major errors in assessing sodium balance, a plausible explanation is intracellular sequestration of sodium.

\section{SYSTEMIC CAPILLARY LEAK AND SYSTEMIC INFLAMMATORY RESPONSE SYNDROME}

The microcirculation after injury is compromised by interstitial oedema due to an increase in systemic capillary permeability, and in severe illness, cellular oedema may further limit capillary blood flow. Systemic capillary leak is a feature of the inflammatory response to localised injury, infection, or ischaemia-reperfusion injury. It occurs within

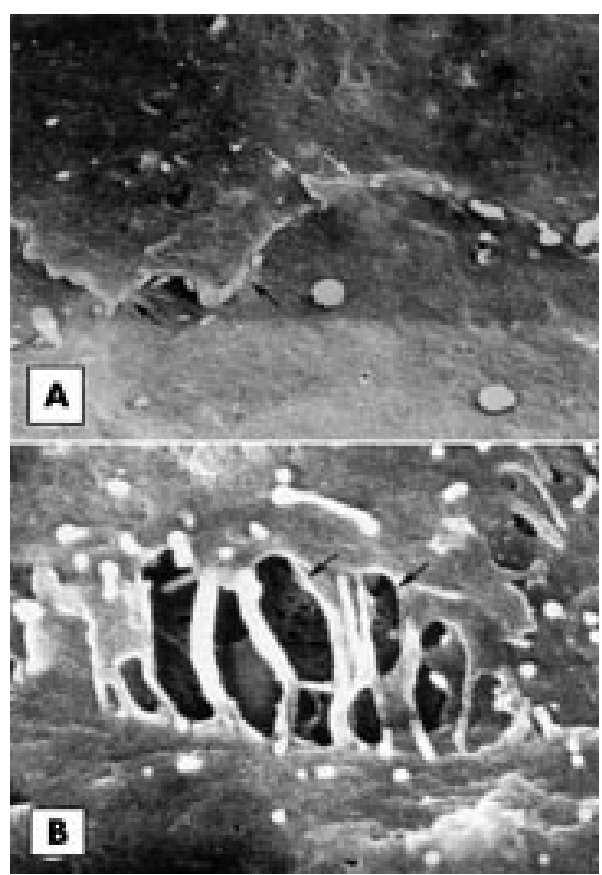

Figure 8 Scanning electron micrographs of a normal rat trachea capillary endothelial junction (A) and one minute after neurogenic inflammation (B) showing intercellular gaps and finger-like processes (Taken with permission from reference 12). minutes of injury, is proportional to the severity of the insult, and in uncomplicated cases resolves within a few hours. ${ }^{10}$ Clinical capillary leak syndrome is characterised by a more extensive movement of water and protein from the vascular space into the interstitium with associated hypoalbuminaemia, increased packed cell volume, hypovolaemia, and accumulation of interstitial oedema fluid. ${ }^{11}$ Although the mechanisms that lead to inflammation induced capillary leak are unclear, recent work has clarified the endothelial cell response to inflammatory mediator release. ${ }^{12}$ After in vivo neurogenic inflammatory stimulation with substance $P$, endothelial cells in the rat trachea were studied by scanning electromicrosopy. Figure 8 shows clear evidence for interendothelial cell gap formation in the inflamed endothelial cell. Through these endothelial cell gaps plasma proteins migrate, the most abundant being albumin. Every gram of albumin "binds" 18 grams of isotonic fluid, which is a further important mechanism leading to salt and water retention and interstitial oedema. As in normality $60 \%$ of the body's albumin is in the interstitial space, and this proportion rises after injury or sepsis due to capillary leak, albumin solutions are not an ideal choice for effective expansion of the vascular compartment.

Interstitial oedema compromises organ function by limiting capillary blood flow, gas exchange, and tissue oxygenation. This is particularly important in the lungs causing ARDS and in the kidneys, where interstitial oedema produces a rise in intrarenal pressure that opposes the filtration pressure driven by the heart. ${ }^{14}$ Clinical capillary leak syndrome reflects a loss of local control of inflammation, and forms part of the exaggerated systemic inflammatory response known as systemic inflammatory response syndrome (SIRS). SIRS is associated with fluid overload, oedema, multiple organ failure, and death when there is failure to maintain homeostasis. ${ }^{15}$

The unique nature of the renal concentrating mechanism allows low level albumin excretion (microalbuminuria) to be used as a sensitive monitor of changes in systemic capillary permeability in patients after trauma, burn injury, surgery, ischaemia-reperfusion and other inflammatory conditions such as acute pancreatitis. These studies demonstrated that microalbuminuria occurs within minutes of the inflammatory insult, is proportional to the severity of the initiating condition, and is predictive of outcome such as ARDS after trauma, ${ }^{16}$ pulmonary dysfunction after elective surgery, ${ }^{17}$ acute myocardial infarction, ${ }^{18}$ multiple organ failure, ${ }^{19} 20$ and death on admission to the ICU. ${ }^{21}$ Figure 9 shows typical patterns of response to injury of systemic capillary permeability (microalbuminuria) and inflammatory mediators (plasma interleukin 6) and markers (serum $\mathrm{C}$ reactive protein).

Failure to excrete the fluid, sodium and chloride load after resuscitation, may be iatrogenic or be due to the effects of an exaggerated inflammatory response. Whatever the cause of fluid overload and oedema, once the process has been started, it becomes a self perpetuating cycle (see box)

\section{EFFECTS OF SODIUM AND CHLORIDE LOADING}

Intravenous volume expansion fluids must be isotonic with plasma. This is achieved by including sodium in the fluid in the $130-150 \mathrm{mmol} / \mathrm{l}$ range, with chloride as the principal anion. While fluid resuscitation is clearly essential, the additional sodium, chloride, and water ultimately have to be excreted if the patient is to recover. Aggressive intravenous fluid administration, in patients who are actively conserving sodium and water, can lead to overload. Over 50 years ago Wilkinson described the inability of surgical patients to excrete a salt and water load until recovery. ${ }^{22}$ Moore described "the sodium retention phase" and the "the sodium diuresis phase" of injury, and observed that the ability to excrete sodium chloride and water heralded recovery. ${ }^{23}$ After major surgery or trauma, there is a risk of oedema affecting the 


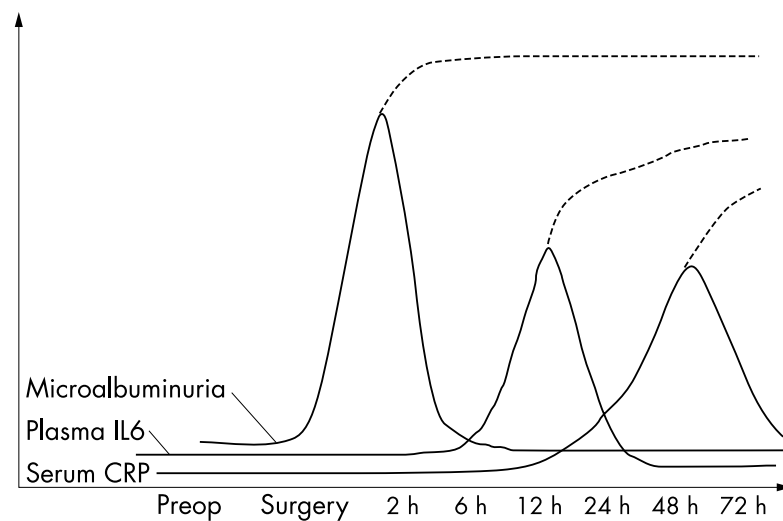

Figure 9 Changes in inflammatory markers after an acute inflammatory insult such as surgery. The continuous lines represent the response to injury leading to uncomplicated recovery, the dotted lines indicate an exaggerated response, characteristic of the loss of homeostatic control of inflammation in systemic inflammatory response syndrome (SIRS). Note how failure of capillary permeability to return to baseline is an early feature of SIRS. Systemic capillary permeability is assessed by low level albumin excretion (microalbuminuria).

lungs, kidneys, and gut, and this danger is increased by injudicious loading with excessive sodium, chloride, and water.

Restricting sodium input and use of diuretics are mainstays of treatment for both congestive heart disease and liver disease in order to limit oedema and ascites respectively. ${ }^{24} 25$ However, the potential harm sodium, chloride, and water loading can cause in trauma victims is less widely appreciated.

Severe sodium and water retention are associated with interstitial oedema, poor lung function, ARDS, and multiple organ failure. A recent review highlighted that, patients with a positive fluid balance greater than $67 \mathrm{ml} / \mathrm{kg} /$ day within the first 36 postoperative hours, are at greater risk of pulmonary oedema. ${ }^{26}$ This raises the question "To what extent is administration of large volumes of sodium and water an unavoidable consequence of treating the acutely ill patient and to what extent is it an avoidable cause of interstitial oedema, organ dysfunction and a poor outcome?"

Recent studies in both normal and critically ill patients suggest that loading with sodium, chloride, and water have deleterious effects, and that limiting sodium and chloride input is beneficial. In a double blind cross over study, 10

\section{Box How fluid overload can lead to oedema}

\section{Cardiovascular}

- Increased preload reduces cardiac output $\rightarrow$ oedema

- Pulmonary oedema $\rightarrow$ tissue hypoxia $\rightarrow$ microvascular failure $\rightarrow$ tissue oedema

\section{Microvascular/cellular}

- Interstitial oedema reduces capillary blood flow $\rightarrow$ tissue hypoxia $\rightarrow$ worsening oedema

- Interstitial oedema reduces lymphatic drainage $\rightarrow$ worsening oedema

- Intrarenal oedema causes high intracapsular pressure: low GFR, oliguria, further sodium and water retention $\rightarrow$ worsening oedema

Metabolic

- Sodium load competes with urea for renal excretion: uraemia, hypernatraemia, hyperosmolarity, fluid retention $\rightarrow$ worsening oedema

- Chloride load leads to hyperchloraemic acidosis: worsens post-trauma acidosis, renal vasoconstriction causes fluid retention $\rightarrow$ worsens oedema healthy volunteers were randomised to receive two litres of $0.9 \%$ sodium chloride and two litres of 5\% dextrose intravenously over 60 minutes. ${ }^{27}$ Six hours after the saline infusion, only one quarter of the fluid load had been excreted, but six hours after the dextrose infusion, three quarters of the fluid load was excreted by a prompt diuresis. Only saline loading was also accompanied by hypernatraemia, hyperchloraemia, and a sustained fall in serum albumin concentration. Comparison of intravenous infusion with $50 \mathrm{ml} / \mathrm{kg}$ of $0.9 \%$ saline (sodium and chloride $154 \mathrm{mmol} / \mathrm{l}$ ) or Ringer's lactate solution (sodium $130 \mathrm{mmol} / \mathrm{l}$ and chloride $113 \mathrm{mmol} / \mathrm{l}$ ) in normal subjects showed the saline treated subjects developed a hyperchloraemic metabolic acidosis. ${ }^{28}$ These effects are in keeping with the theoretical physiological response to sodium and chloride loading. Misnamed "normal saline" the supranormal sodium and chloride content, with an osmolality of $304 \mathrm{mosm} / \mathrm{kg}$, stimulates vasopressin release and leads to fluid conservation. Hyperchloraemia causes renal vasoconstriction, which may be another mechanism leading to fluid retention after a saline load. ${ }^{29}$ The salt content of colloidal solutions also influences acid base status. Waters et al compared intravenous administration of $15 \mathrm{ml} / \mathrm{kg}$ of either $6 \%$ hydroxyethyl starch (chloride content $150 \mathrm{mmol} / \mathrm{l}$ ) and human albumin (chloride content $98 \mathrm{mmol} / \mathrm{l}){ }^{30}$ Only the starch group showed a metabolic acidosis, which was attributed to the high chloride content of human albumin.

The sodium and water content of preoperative intravenous feeding in malnourished patients has been shown to influence outcome. Lobo et al studied retrospectively 44 patients referred for nutritional support of whom 21 were oedematous. ${ }^{31}$ Nutritional support for the odematous group included a low volume and low sodium feed. The oedematous group's mean weight fell by $10 \mathrm{~kg}$ because of mobilisation of sodium and water, with a pronounced rise in serum albumin concentration, which was significantly associated with the change in weight. Gil et al randomised 41 patients with gastrointestinal cancer and severe malnutrition to two isocalorific and isonitrogenous preoperative parenteral regimens. ${ }^{32}$ The standard regimen contained $140 \mathrm{mmol} / \mathrm{day}$ of sodium and the modified regimen contained no additional sodium and less water. Weight gain, positive fluid balance, and positive sodium balance were found in the standard regimen group, and there was a negative fluid and sodium balance in the modified regimen group. There were reduced postoperative complications and hospital stay in the patients assigned to the modified regimen. Starker et al monitored the effects of an average of one week's total parenteral nutrition before a major abdominal operation in 32 nutritionally depletion patients. ${ }^{33}$ These patients were followed up for postoperative complications. Sixteen patients responded to TPN by mobilisation of oedema and a rise in serum albumin, and only one suffered a postoperative complication. The other 16 patients gained weight after TPN and their serum albumin fell. Of these eight patients developed a total of 15 postoperative complications. Failure to mobilise oedema in response to parenteral nutrition carries a poor prognosis.

These reports indicate that limitation of sodium, chloride, and fluid input can influence outcome. What is disturbing is the lack of understanding of the basic properties of different intravenous fluids, in the UK at least, ${ }^{34}$ and the frequent failure to use urinary nitrogen and electrolyte measurements to optimise fluid therapy.

\section{HYPERTONIC SOLUTIONS}

Despite the deleterious effects of sodium and chloride loading, increasing the plasma tonicity in the early post-trauma period has been claimed to affect organ function, and has been the subject of study for nearly 20 years. Clinical studies after head trauma suggest that early infusion of hypertonic solutions 
reduce intracranial pressure, increase cerebral perfusion pressure, and improve outcome, compared with isotonic resuscitation. ${ }^{35-37}$ However, in patients with head injury who are also hypovolaemic, hypertonic solutions are only of benefit during early care, and should not be the sole form of resuscitation. ${ }^{38}$

Clinical studies of the use of hypertonic solutions for treatment of hypovolaemic shock have not shown consistent benefit in terms of mortality or morbidity, however this may be attributable to the complexities of the clinical models used and the variable effects of hypertonic solutions.

To test the effect of different fluid resuscitation regimens on morbidity and mortality, large numbers of patients are required for clinical studies to have sufficient power. An additional difficulty is the wide variety of fluid treatments used for "standard care", which makes the choice of the control arm regimen equally important as the intervention. Consequently it is not surprising that consistent benefit has not been found with hypertonic solutions. Several studies have shown that inclusion of hypertonic saline, with or without a colloid such as dextran, in resuscitation for trauma, haemorrhagic shock, or burn injury reduces the volume of fluid required, ${ }^{39} 40$ and in some improves lung function. ${ }^{41}$ The mechanism underlying these apparent benefits in clinical studies is not clear, but seems unlikely to be simply attributable to biophysical/ osmotic effect of limiting interstitial oedema, as the volume of hypertonic fluid given is small. ${ }^{42}$ In addition, infusion of hypertonic solutions to "steal" fluid from the interstitial space to expand the depleted vascular compartment will be of only short-term benefit, and the underlying deficit still has to be corrected.

Recent evidence from clinical, animal, and in vitro studies suggest that the manipulation of the plasma osmolality (tonicity) in the very early post-trauma period has an immunomodulatory effect, which influences the microcirculation, and potentially may effect outcome. ${ }^{43}$ Early administration of hypertonic saline, with or without dextran, followed by haemorrhagic shock in an animal model, reduced neutrophil endothelial cell adherance. ${ }^{44}$ However, hypertonic saline given after neutrophil stimulation, increases neutrophil degranulation, elastase release, and free radical production: processes thought to be at the heart of the pathogenesis of lung injury and organ failure. ${ }^{45} 46$ Thus use of hypertonic solutions to attenuate the proinflammatory immune response is probably critically dependent on the time after injury, and administration too late may heighten the risk of later organ failures. ${ }^{47}$ The critical timing may be an additional explanation for the conflicting results from earlier clinical studies of hypertonic resuscitation regimens.

In vitro studies also suggest that hypertonic saline affects post-traumatic immune suppression. Post-trauma suppressed human $\mathrm{T}$ cells, and cells suppressed artificially by antiinflammatory cytokines (interleukins 4 and 10, and transforming growth factor), can be up regulated by hypertonic saline to produce $80 \%$ of their normal interleukin 2 output. Only in the presence of anti-inflammatory agents does hypertonic saline augment $\mathrm{T}$ cell interleukin 2 expression and proliferation. ${ }^{48}$ Further studies indicate that hypertonic saline can "resuscitate" suppressed T cells in trauma patients by circumvention of, or substituting for, blocked signalling pathways. ${ }^{49}$

These results suggest that hypertonic solutions may be of value in acute hypovolaemia, provided, they are given before fluid resuscitation: delayed administration may accentuate the activated neutrophil-endothelial cell inflammatory response. Perhaps hypertonic saline solutions should not be considered as a form of fluid resucitation, but rather a drug, which may have a role in immune attenuation if given as soon as possible after insult before volume therapy is started. This information should influence the design of future clinical trials of hypertonic solutions in prehospital and hospital trauma care.

\section{EFFECTS OF DIFFERENT COLLOIDS}

From the middle of the past century, human albumin solutions were the main colloids used for volume expansion, and the search for synthetic alternatives was principally driven by cost, human albumin being more expensive than synthetic colloids or crystalloid solutions. ${ }^{50}$ More recently the risk of infection from human blood products has added to the demand for synthetic alternatives. The ideal properties for a volume expander are that it remains in the vascular space, does not affect haemostasis, is inert, and is excreted completely. This lead to the development of a variety of colloids including low molecular weight gelatines with average molecular weight $30 \mathrm{kDa}$, dextrans with average molecular weights ranging from $40 \mathrm{kDa}$ to $150 \mathrm{kDa}$ and a variety of hydroxyethyl starch (HES) preparations with average molecular weights ranging from $70 \mathrm{kDa}$ to $450 \mathrm{kDa}$. High molecular weight HES solutions, also known as hetastarches, are retained in the circulation for many hours and tend to affect coagulation, ${ }^{51}$ but this is less of a problem with more recent HES preparations with mean molecular weights of around $100 \mathrm{kDa}$ to $200 \mathrm{kDa}$ and lower hydroxyethyl substitution ratios that speed up in vivo degradation and excretion..$^{52-54}$ In general there is ignorance of the different properties of synthetic colloids, with cost and anecdotal experience determining which is used in different clinical settings rather than clinical efficacy. However, over the past decade the effects of different colloids on the inflammatory response and organ function have been observed, ${ }^{55}$ and have lead to prospective clinical comparative studies.

Evidence from clinical and in vitro studies comparing HES with albumin, gelatines, and crystalloid only volume expansion, suggest that HES reduces inflammation induced capillary leak of water and albumin, ${ }^{56}$ possibly by modulating cytokine release $^{57}$ and the interaction of leucocytes with vascular endothelium..$^{58} 59$

HES may have a distinct clinical benefit over other fluids, which cannot simply be attributed to the biophysical properties of HES being better retained by the leaking vascular tree. Boldt et al randomised 30 trauma and 30 sepsis patients to receive either 10\% HES (mean molecular weight $200 \mathrm{kDa}$ ) or $20 \%$ human albumin, infused over five days to keep pulmonary capillary wedge pressure between $12 \mathrm{~mm} \mathrm{Hg}$ and $18 \mathrm{~mm} \mathrm{Hg} .{ }^{60}$ Central venous pressure and pulmonary capillary wedge pressure were comparable within the subgroups (trauma/sepsis) throughout the entire study period. In both trauma and sepsis patients, cardiac index, oxygen consumption, and oxygen delivery, significantly increased only in the HES treated patients. Right ventricular ejection fraction was reduced $(<40 \%)$ in the albumin treated patients and increased only in the HES group. Intramucosal gastric pHi, a marker of splanchnic perfusion, remained normal $(>7.35)$ in both albumin and HES treated trauma groups and in the HES treated sepsis patients. In the albumin treated sepsis group, $\mathrm{pHi}$, fell below 7.20 within the study period, indicating reduced splanchnic perfusion. The authors concluded that long term intravascular fluid therapy with albumin in trauma and sepsis patients has no advantages in comparison with HES. In both groups, volume replacement with HES resulted in improved systemic haemodynamics, and in sepsis patients improved splanchnic perfusion.

In a prospective randomised trial of HES versus crystalloid volume replacement in 30 patients undergoing aortic surgery, Marik et al also studied splanchnic perfusion by pHi measurements. ${ }^{61}$ The fall in pHi was significantly less in the HES group, and the intraoperative positive fluid balance was significantly less in the HES treated group. These authors also concluded that during major surgery, volume resuscitation with HES may improve microvascular blood flow and tissue oxygenation compared with crystalloid only regimens.

In addition to measuring $\mathrm{pHi}$ and haemodynamic parameters, Boldt et al also studied liver function and circulatory 
regulators in trauma $(\mathrm{n}=28)$ and sepsis $(\mathrm{n}=28)$ patients randomised to albumin and HES resuscitation. ${ }^{62}$ Plasma concentrations of vasopressin, endothelin-1, adrenaline (epinephrine), noradrenaline (norephinephrine), atrial natriuretic peptide, and 6-keto-prostaglandin $\mathrm{F}_{1} \alpha$ were measured on the day of admission to the intensive care unit (trauma patients) or on the diagnosis of sepsis, and daily for the next five days. Liver function was assessed daily using the monoethylglycinexylidide test (MEGX). Mean arterial pressure, heart rate, and pulmonary capillary wedge pressure did not differ between the corresponding subgroups (trauma/sepsis). Cardiac index increased significantly more in the HES than in the albumin groups. pHi and MEGX plasma concentrations did not differ in the two groups of trauma patients, but both were lower than normal in the sepsis groups and increased more markedly in the HES than in the albumin treated patients. In the trauma patients, concentrations of all vasoactive regulators were very similar in both albumin and HES treated groups. In both sepsis groups, vasopressors (vasopressin, endothelin-1, noradrenaline, and adrenaline) were significantly increased above normal at baseline and decreased more markedly in HES than in albumin treated patients. Concentrations of atrial natriuretic peptide increased only in the albumin treated patients, while plasma concentrations of 6-keto-prostaglandin $\mathrm{F}_{1} \alpha$ decreased significantly only in the HES sepsis patients. These results suggested that HES was a more effective volume expander than albumin, particularly in sepsis patients.

Younes et al studied trauma patients with haemorrhagic hypovolaemia randomised to HES $(n=12)$ or isotonic saline $(\mathrm{n}=11) .{ }^{63}$ Fluid was infusing in $250 \mathrm{ml}$ boluses until systolic blood pressure was $>100 \mathrm{~mm} \mathrm{Hg}$. While death rates were similar in both groups, significantly less fluid was required in the HES treated patients, which is consistent with the better vascular retention of HES compared with saline.

In a randomised prospective study, the author's group compared resuscitation with HES ( $10 \%$ Pentaspan) $(n=20)$ or gelatine $(n=21)$ for the first 24 hours in patients suffering blunt trauma. ${ }^{64}$ Capillary permeability, assessed by the median six hourly urine albumin excretion rate, was reduced by half during the first 8-12 hours in the HES group. After 48 hours the mean $\mathrm{pO}_{2} / \mathrm{FiO}_{2}$ ratio was significantly higher for the HES group and the mean serum $\mathrm{C}$ reactive protein significantly lower. There were no significant differences in coagulation markers throughout the first five days. Further studies in patients undergoing elective abdominal aortic aneurysm repair, randomised to receive eloHAES or gelatine for the first 24 hours, showed a similar reduction in perioperative systemic capillary permeability, higher lung compliance, higher $\mathrm{pO}_{2} /$ $\mathrm{FiO}_{2}$ ratio and higher pHi suggesting less splanchnic ischaemia. ${ }^{65}$ The HES group also showed lower postoperative circulating interleukin 6, C reactive protein and von Willebrand factor concentrations, suggesting an antiinflammatory and vascular endothelial protecting effect in HES treated patients. ${ }^{66}$ Mean serum creatinine concentrations were also lower in the HES treated patients. ${ }^{67}$ In a study of trauma patients randomised to HES $(n=15)$ or $20 \%$ human albumin $(n=15)$ for volume therapy, plasma concentrations of endothelial leucocyte adhesion molecules (sELAM-1), intercellular adhesion molecule-1 (sICAM-1), vascular cell adhesion molecule-1 (sVCAM-1), and granule membrane protein 140 (sGMP-140) were significantly lower in the HES group over five days. ${ }^{68}$ These studies indicate that, compared with albumin, gelatine, or crystalloid only regimens, resuscitation with medium molecular weight HES reduces post-trauma capillary leak, improves pulmonary gas exchange, reduces splanchnic ischaemia and has an anti-inflammatory effect.

Volume expansion with high molecular weight hetastarches has been associated with coagulopathy, ${ }^{59}$ however two studies comparing medium molecular weight HES with gelatine for trauma resuscitation ${ }^{64}$ or during major orthopaedic surgery ${ }^{69}$ have shown no differences in laboratory markers of coagula- tion. Because of the widespread lack of awareness of the different properties of colloids, there are dangers in the use of HES without sufficient free water input. Where HES forms the major component of the fluid infused, there is a risk of cellular dehydration, with reports of impaired renal function associated with an osmotic nephrosis. ${ }^{70}{ }^{71}$ HES solutions are effective volume expanders but on their own do not provide sufficient water for urine formation. Failure to provide adequate free water input can lead to renal impairment. In studies, which have shown HES solutions to be of benefit over other colloids, HES constituted only about one third of the total volume of fluid infused. ${ }^{72}$ Additional studies are required to identify the mechanism by which HES appears to have anti-inflammatory properties, protecting the microvasculature during acute inflammatory states such as trauma and sepsis. However, there is sufficient evidence from clinical studies to draw some practical recommendations for optimising resuscitation and post-resuscitation fluid regimens.

\section{RESUSCITATION}

Limit sodium, chloride, and fluid input where possible, by including a narrow range, medium molecular weight HES in the resuscitation regimen. Volume expansion with HES reduces the fluid and sodium load compared with gelatines, $4.5 \%$ albumin, or crystalloid only resuscitation. This recommendation is consistent with the ATLS guidelines for two litres of warmed Hartmann's solution to be given for immediate fluid resuscitation, but suggests that for major fluid resuscitation overall, one third of all the fluid infused (excluding red cells) should be medium molecular weight HES. Use of hypertonic solutions in head injuries is probably beneficial, but cannot be used as the sole form of resuscitation. The use of hypertonic solutions for early treatment of hypovolaemia remains to be shown to be of benefit, and any immune modulatory effect may be critically dependent on the time of administration after injury.

\section{AFTER RESUSCITATION}

- Aim for a negative fluid and sodium balance, when haemodynamic stability has been restored and the inflammatory response has subsided, in order to mobilise resuscitation and perioperative sodium and water load. This is typically between days 2 and 5 post-trauma or surgery in uncomplicated cases.

- Review sodium and fluid balance every 24 hours. Allow $800 \mathrm{ml}$ per day for insensible losses, and increase by 200 $\mathrm{ml}$ for every ${ }^{\circ} \mathrm{C}$ above $37^{\circ} \mathrm{C}$. (More for burns patients)

- Provide maintenance water for urine and to replace insensible losses, enterally or in combination with intravenous $5 \%$ dextrose.

- Monitor urine volume, sodium, potassium, and urea excretion each day until intravenous therapy is no longer required. If urine osmolality rises above $500 \mathrm{mosm} / \mathrm{l}$, urine sodium falls below $50 \mathrm{mmol} / 24 \mathrm{~h}$ with rising serum sodium and urea concentrations consider increasing free water input.

- If a negative sodium and water balance is difficult to achieve, consider using a diuretic.

Remember serum sodium and potassium concentrations do not reflect total body status, which is why it is essential to compare fluid input with urinary excretion of electrolytes and urea.

\section{SIGNS OF FLUID OVERLOAD IN TRAUMA VICTIMS Prolonged positive fluid balance}

The normal blood volume of an adult male is about five litres, of which plasma represents about 2.8 litres. After correction for estimated blood losses and insensible losses, 24 hours post-resuscitation patients typically show a positive fluid balance of four to six litres. This is due to the trauma induced 


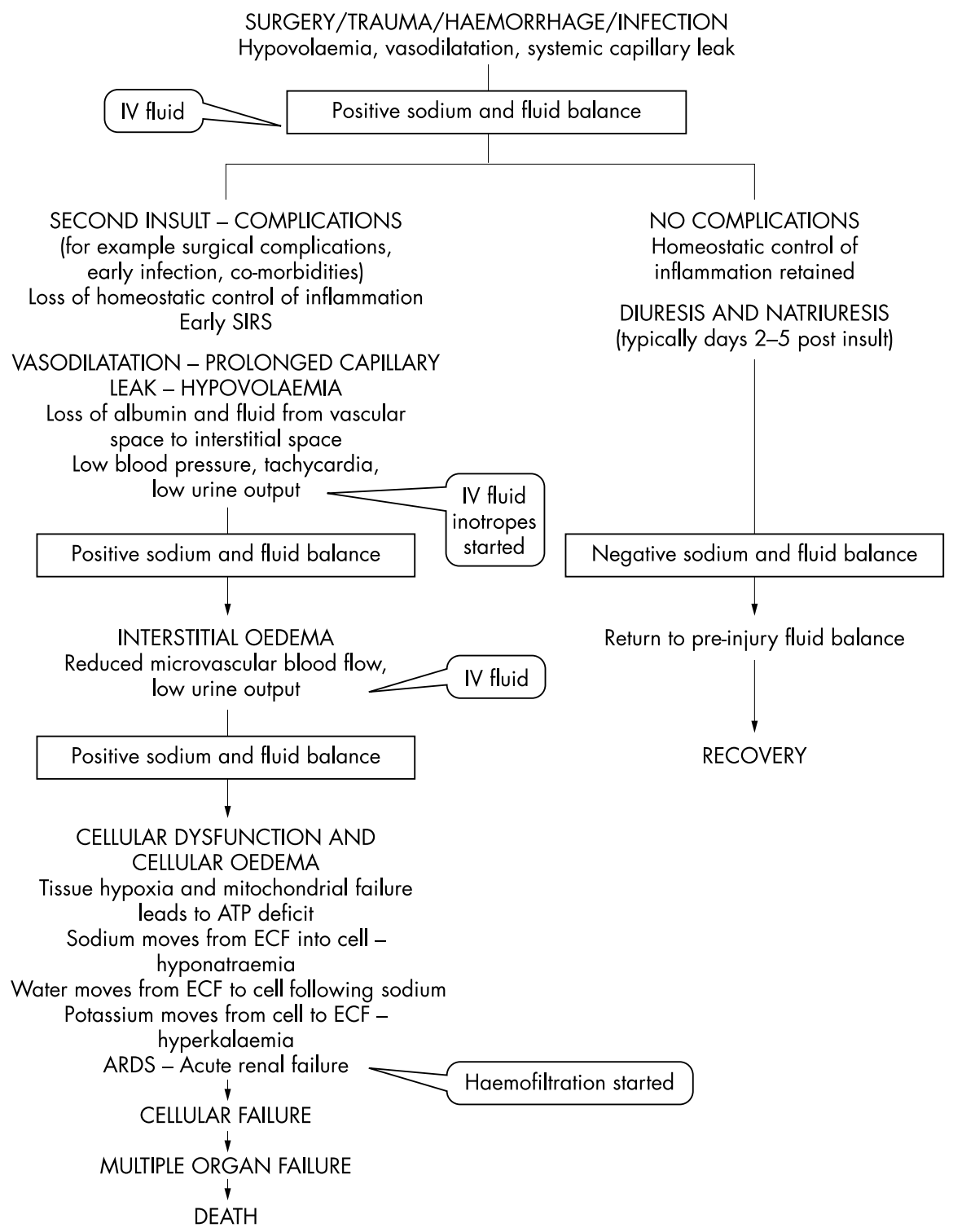

Figure 10 Summary of the fluid and electrolyte responses to acute injury leading to recovery or systemic inflammatory response syndrome (SIRS), acute respiratory distress syndrome (ARDS), multiple organ failure (MOF) and death. (ECF, extracellular fluid). increase in systemic capillary permeability causing a shift of fluid from the vascular to the interstitial compartment. This fluid load should be excreted within the next two to five days provided the inflammatory response has subsided and microvascular function has returned to normal. A prolonged and increasing positive fluid balance indicates worsening fluid overload: this may be iatrogenic and avoidable, or be attributable to a sustained capillary leak as part of SIRS together with loss of systemic vascular resistance (fig 10).

\section{Pulmonary wedge pressure}

In the absence of conditions such as cardiac tamponade, left ventricular failure, mitral valve stenosis or pericarditis, high pulmonary wedge pressures suggest fluid overload. (NB correction should be made for positive end expiratory pressure).

\section{Cardiac stroke volume}

The effect of $200 \mathrm{ml}$ boluses of hydroxethyl starch on cardiac stroke volume measured by oesophageal Doppler can be used to optimise pre-load, and in cardiac and orthopaedic surgery has been shown to improve outcome. ${ }^{73} 74$ Failure of vascular expansion to increase stroke volume indicates adequate or excessive vascular expansion and should limit further attempts to expand the vascular compartment.

\section{Weight gain}

Provided a weigh bed is available and readings can be corrected for dressings and monitoring equipment, weight gain can be used as an estimate of fluid balance. This is especially valuable in burn patients whose insensible losses are otherwise unmeasurable.

\section{CONCLUSIONS}

Injury causes pathophysiological responses directed towards preservation of the blood supply to essential organs, this includes sodium and water retention. The response to injury and infection also causes an increase in systemic capillary permeability to plasma proteins and fluid, which becomes out of control early in SIRS and leads to salt and water overload and interstitial oedema. Although sodium, chloride, and water loading are unavoidable in treatment of an acute insult, the later deleterious effects of salt and fluid overload can be limited. Strategies include using medium molecular weight HES in combination with Hartmann's solution for resuscitation, assessing the adequacy of volume replacement by clinical and haemodynamic monitoring and avoiding unnecessary infusion of salt containing fluids. Post-resuscitation aims should be to off load interstitial salt and water as soon as the 
inflammatory response has subsided, capillary leak has returned to normal and the patient is haemodynamcally stable. During recovery, care must be taken to provide enough free water to maintain sufficient urine output to excrete the resuscitation sodium load as well as the increased nitrogen excretion associated with trauma, major surgery, or sepsis.

\section{REFERENCES}

1 Cochrane Injuries Group Albumin Reviewers. Human albumin administration in critically ill patients: systematic review of randomised controlled trials. BM 1998:317:235-40.

2 See correspondence. Fluid resuscitation with colloid or crystalloid. BM 1998; 317:277-9

3 Tietz N W, ed. Clinical guide to laboratory tests. 3rd edn. Philadelphia: W B Saunders, 1995

4 Stoneham MD, Hill EL. Variability in post-operative fluid and electrolyte prescribing. Br J Clin Pract 1977:51:82-4.

5 Bowyer MW. Fluid therapy. In: Parsons PE, Wiener-Kronish JP, eds. Critical care secrets. St Lovis: Mosby-Year Book, 1998: 26

6 Flear CT, Singh CM. Hyponatraemia and sick cells. Br J Anaesth 1973;45:976-94.

7 Cunningham JN, Shires GT, Wagner Y. Changes in intracellular sodium and potassium content of red blood cells in trauma and shock. Am J Surg 1971;122:650-4.

8 Brown GC. Nitric oxide as a competitive inhibitor of oxygen consumption in the mitochondrial respiratory chain. Acta Physiol Scand 2000;168:667-74

9 Hannon RJ, Boston VE. Fluid and ion redistribution in skeletal muscle in an animal sepsis model. J Pediatr Surg 1990;25:599-603.

10 Fleck A, Raines G, Hawker F, et al. Increased vascular permeability; a major cause of hypoalbuminaemia in disease and injury. Lancet 1985;i:781-3.

11 Zikria BA, Bascom JU. Mechanisms of multiple organ failure. In: Zikria $\mathrm{BA}, \mathrm{Oz}$ MC, Carlson RW, eds. Reperfusion injuries and clinical capillary leak syndrome. Armonk, NY: Futura, 1994:443-92.

12 McDonald DM, Thurston G, Baluk P. Endothelial gaps as sites for plasma leakage in inflammation. Microcirculation 1999;6:7-22.

13 Gosling P. Albumin: friend or foe? Trauma 2000;2:125-34.

14 Stone HH, Fulenwider JT. Renal decapsulation in the prevention of post ischaemia oliguria. Ann Surg 1977; 186:343-55

15 Davies MG, Hagen PO. Systemic inflammatory response syndrome. $\mathrm{Br} J$ Surg 1997;84:920-35.

16 Pallister I, Gosling P, Alpar K, et al. Prediction of post traumatic adult respiratory distress syndrome by albumin excretion rate eight hours after admission. J Trauma 1997;42:1056-61

17 Smith CT, Gosling P, Sanghera K, et al. Microproteinuria predicts the severity of systemic effects of reperfusion injury following infra renal aortic aneurysm surgery. Ann Vasc Surg 1994:8:1-5.

18 Gosling P, Hughes EA, Reynolds TM, et al. Microalbuminuria is an early response following acute myocardial infarction. Eur Heart $J$ $1991 ; 12: 508-13$.

19 MacKinnon KL, Molnar Z, Lowe D, et al. Use of microalbuminuria as a predictor of outcome in critically ill patients. Br J Anaesth 2000;84:239-41.

20 Adid O, Sun Q, Sugimoto K, et al. Predictive value of microalbuminuria in medical ICU patients: results of a pilot study. Chest $2001 ; 120: 1984-$ 8.

21 Gosling P, Brudney S, McGrath L, et al. Mortality prediction on admission to intensive care: a comparison of microalbuminuria with acute physiology scores after 24 hours. Crit Care Med 2003:31:98-103.

22 Wilkinson AW, Billing BH, Nagy G, et al. Excretion of chloride and sodium after surgical operations. Lancet 1949;i:640-4.

23 Moore FD. Metabolic care of the surgical patient. Philaldelphia: W B Saunders, 1959.

24 Frye RL. Chronic congestive heart failure. Eight steps in management Postgrad Med 1981:69:165-169.

25 Yu AS, Hu KQ Management of ascites. Clin Liver Dis 2001;5:541-68 i.

26 Arieff Al. Fatal postoperative pulmonary oedema: pathogenesis and literature review. Chest 1999;115:1371-7.

27 Lobo DN, Stanga Z, Simpson JAD, et al. Dilution and redistribution effects of rapid 2-litre infusions of $0.9 \%(\mathrm{w} / \mathrm{v})$ saline and $5 \%(\mathrm{w} / \mathrm{v})$ dextrose on haematological parameters and serum biochemistry in normal subjects: a double-blind crossover study. Clin Sci 2001;101:173-9.

28 Williams EL, Hildebrand KL, McCormick SA, et al. The effect of intravenous lactated Ringer's solution versus $0.9 \%$ sodium chloride solution on serum osmolality in human volunteers. Anesth Analg 1999:88:999-1003.

29 Wilcox CS. Regulation of renal blood flow by plasma chloride. J Clin Invest 1983;71:726-35.

30 Waters JH. Bernstein CA. Dilutional acidosis following hetastarch or albumin in healthy volunteers. Anesthesiology 2000;93:1 184-7.

31 Lobo DN, Bjarnason K, Field J, et al. Changes in weight, fluid balance and serum albumin in patients referred for nutritional support. Clin Nutr 1999; 18:1970-201.

32 Gill MJ, Franch G, Guirao X, et al. Response of severely malnourished patients to preoperative parenteral nutrition: a randomized clinical trial of water and sodium restriction. Nutrition 1997;13:26-31.
33 Starker PM, Lasala PA, Askanazi J, et al. The response to TPN. A form of nutritional assessment. Ann Surg 1983;198:720-4.

34 Lobo DN, Dube MG, Neal KR, et al. Problems with solutions: drowning in the brine of an inadequate knowledge base. Clin Nutr 2000;20:125-30.

35 Wade CE, Grady JJ, Kranmer GC, et al. Individual patient cohort analysis of the efficacy of hypertonic saline/dextran in patients with traumatic brain injury and hypotension. J Trauma 1997:42:S61-5.

36 Simma B, Burger $R$, Falk $M$, et al. A prospective, randomized, and controlled study of fluid management in children with severe head injury: lactated Ringer's solution versus hypertonic saline. Crit Care Med 1998;26: 1265-70.

37 Peterson B, Khanna S, Fisher B, et al. Prolonged hypernatremia controls elevated intracranial pressure in head-injured pediatric patients. Crit Care Med 2000;28: 1 136-43.

38 Favre JB, Ravussin P, Chiolero R, et al. Hypertonic solutions and intracranial pressure. Schweiz Med Wochenschr 1996;1 26:1635-43.

39 Cross JS, Gruber DP, Burchard KW, et al. Hypertonic saline fluid therapy following surgery: a prospective study. J Trauma 1989;29:817-25.

40 Vassar MJ, Fischer RP, O'Brien PE, et al. Multicenter trial for resuscitation of injured patients with $7.5 \%$ sodium chloride. The effect of added dextran 70. The Multicenter Group for the Study of Hypertonic Saline in Trauma Patients. Arch Surg 1993;128:1003-11.

41 Shimazaki S, Yukioka T, Matuda H. Fluid distribution and pulmonary dysfunction following burn shock. J Trauma 1991;31:623-6.

42 Scalia SV, Taheri PA, Force S, et al. Mesenteric microcirculatory change in nonlethal hemorrhagic shock: the role of resuscitation with balanced electrolyte or hypertonic saline/dextran. J Trauma $1992 ; 33: 321-5$.

43 Rotstein OD. Novel strategies for immunomodulation after trauma: revisiting hypertonic saline as a resuscitation strategy for hemorrhagic shock. J Trauma 2000;49:580-3.

44 Corso CO, Okamoto S, Rüttinger D, et al. Hypertonic saline dextran attenuates leukocyte accumulation in the liver after hemorrhagic shock and resuscitation. J Trauma 1999;46:417-23.

45 Murao Y, Hoyt DB, Loomis W, et al. Does the timing of hypertonic saline resuscitation affect its potential to prevent lung damage? Shock 2000;14:18-23.

46 Partrick DA, Moore EE, Offner PJ, et al. Hypertonic saline activates lipid-primed human neutrophils for enhanced elastase release. J Trauma 1998:44:592-7.

47 Ciesla DJ, Moore EE, Zallen G, et al. Hypertonic saline attenuation of polymorphonuclear neutrophil cytotoxicity: timing is everything. J Trauma 2000;48:388-95

48 Loomis WH, Namiki S, Hoyt DB, et al. Hypertonicity rescues T cells from suppression by trauma-induced anti-inflammatory mediators. Am J Physio Cell Physiol 2001;281:C840-8.

49 Junger WG, Hoyt DB, Hamreus $M$, et al. Hypertonic saline activates protein tyrosine kinases and mitogen-activated protein kinase p38 in T-cells. J Trauma 1997:42:437-43.

50 Thompson WL. Rational use of albumin and plasma substitutes. Johns Hopkins Med J 1975;36:220-5

51 Baldassarre S, Vincent J-L. Coagulopathy induced by hydroxyethyl starch. Anesth Analg 1997;84:451-3.

52 Boldt J, Heesen M, Welters I, et al. Does the type of volume therapy influence endothelial-related coagulation in the critically ill ? Br J Anaesth 1995;75:740-6.

53 Haisch G, Boldt J, Krebs C, et al. Influence of a new hydroxyethyl preparation (HES 130/0.4) on coagulation in cardiac surgery patients. Cardiothorac Vasc Anesth $2001 ; 15: 316-21$.

54 Haisch G, Boldt J, Krebs C, et al. The influence of intravascular volume therapy with a new hydroxyethyl strach preparation (6\% HES 130/0.4) on coagulation in patients undergoing major abdominal surgery. Anesth Analg 2001;92:565-71

55 Traylor RJ, Pearl RG. Crystalloid versus colloid: All colloids are not created equal. Anesth Analg1996:83:209-12.

$56 \mathrm{Oz} \mathrm{MC}$, FitzPatrick MF, Zikria BA, et al. Attenuation of microvascular permeability dysfunction in post-ischemic striated muscle by hydroxyethyl starch. Microvasc Res 1995;50:71-9.

57 Schmand JF, Ayala A, Morrison MH, et al. Effects of hydroxyethyl starch after trauma-hemorrhagic shock: restoration of macrophage integrity and prevention of increased circulating interleukin-6 levels. Crit Care Med 1995;23:806-14

58 Hofbauer R, Moser D, Hornykewyez S, et al. Hydroxyethyl starch reduces the chemotaxis of white cells through endothelial cell monolayers. Transfusion 1999;39:289-94.

59 Collis RE, Collins PW, Gutteridge CN, et al. The effect of hydroxyethyl starch and other plasma volume substitutes on endothelial cell activation: an in vitro study. Intesive Care Med 1994;20:37-41.

60 Boldt J, Heesen M, Muller M, et al. The effects of albumin versus hydroxyethyl starch solution on cardiorespiratory and circulatory variables in critically ill patients. Anesth Analg 1996;83:254-61.

61 Marik PE, Iglesias J, Maini B. Gastric intramucosal pH changes afte volume replacement with hydroxyethyl starch or crystalloid in patients undergoing elective abdominal aortic aneurysm repair. J Crit Care 1997; 12:51-5.

62 Boldt J, Mueller M, Menges T, et al. Influence of different volume therapy regimes on regulators of the circulation in the critically ill. Br J Anaesth 1996;77:480-7. 
63 Younes RN, Yin KC, Amino CJ, et al. Use of pentastarch solution in the treatment of patients with hemorrhagic hypovolaemia: randomised phase II study in the emergency room. World J Surg 1998;22:2-5.

64 Allison K, Gosling P, Jones S, et al. Hydroxyethyl starch reduces capillary leak compared to gelatine solutions during trauma resuscitation. J Trauma 1999:47:1114-21.

65 Rittoo D, Gosling P, Bonnicci C, et al. Splanchnic oxygenation in patients undergoing abdominal aortic anurysm repair and volume expansion with eloHAES. Cardiovasc Surg 2002;10:128-33.

66 Rittoo D, Gosling P, Burnley S, et al. Hydroxyethyl starch reduces endothelial activation in infrarenal aneurysm surgery. Br J Surg 2001;88 (suppl 1):013.

67 Rittoo D, Gosling P, Burnley S, et al. Hydroxyethyl starch solution (eloHAES) reduces renal dysfunction in infrarenal aortic surgery. $\mathrm{Br} J$ Surg (in press)

68 Boldt J, Heesen M, Padberg W, et al. The influence of volume therapy and pentoxifylline infusion on circulating adhesion molecules in trauma patients. Anaesthesia 1996;51:529-35.
69 Beyer R, Harmening U, Rittmeyer O, et al. Use of modified fluid gelatin and hydroxyethyl starch for colloidal volume replacement in major orthopaedic surgery. Br J Anaesth 1997;78:44-50.

70 Cittanova ML, Leblanc I, Legendre C, et al. Effect of hydroxyethylstarch in brain-dead kidney donors on renal function in kidney-transplant recipients. Lancet 1996;348:1620-2.

71 Schortgen F, Lacherade J-C, Bruneel F, et al. Effects of hydroxyethyl starch and gelatinn on renal function in severe sepsis: a multicentre eandomised study. Lancet 2001;357:911-16.

72 Gosling P, Rittoo D, Manji M, et al. Hydroxyethylstarch as a risk factor for acute renal failure in severe sepsis. Lancet 2001;358:581, 582-3.

73 Mythen MG, Webb AR. Perioperative plasma volume expansion reduces the incidence of gut mucosal hypoperfusion during cardiac surgery. Arch Surg 1995;130:423-9.

74 Sinclair S, James S, Singer M. Intraoperative intravascular volume optimisation and length of hospital stay after repair of proximal femoral fracture: randomised controlled trial. BM 1997;315:909-12

\section{Clinical Evidence-Call for contributors}

Clinical Evidence is a regularly updated evidence based journal available worldwide both as a paper version and on the internet. Clinical Evidence needs to recruit a number of new contributors. Contributors are health care professionals or epidemiologists with experience in evidence based medicine and the ability to write in a concise and structured way.

Currently, we are interested in finding contributors with an interest in the following clinical areas:

Altitude sickness; Autism; Basal cell carcinoma; Breast feeding; Carbon monoxide poisoning; Cervical cancer; Cystic fibrosis; Ectopic pregnancy; Grief/bereavement; Halitosis; Hodgkins disease; Infectious mononucleosis (glandular fever); Kidney stones; Malignant melanoma (metastatic); Mesothelioma; Myeloma; Ovarian cyst; Pancreatitis (acute); Pancreatitis (chronic); Polymyalgia rheumatica; Post-partum haemorrhage; Pulmonary embolism; Recurrent miscarriage; Repetitive strain injury; Scoliosis; Seasonal affective disorder; Squint; Systemic lupus erythematosus; Testicular cancer; Varicocele; Viral meningitis; Vitiligo

However, we are always looking for others, so do not let this list discourage you.

Being a contributor involves:

- Appraising the results of literature searches (performed by our Information Specialists) to identify high quality evidence for inclusion in the journal.

- Writing to a highly structured template (about 2000-3000 words), using evidence from selected studies, within 6-8 weeks of receiving the literature search results.

- Working with Clinical Evidence Editors to ensure that the text meets rigorous epidemiological and style standards.

- Updating the text every eight months to incorporate new evidence.

- Expanding the topic to include new questions once every 12-18 months.

If you would like to become a contributor for Clinical Evidence or require more information about what this involves please send your contact details and a copy of your CV, clearly stating the clinical area you are interested in, to Claire Folkes (cfolkes@bmigroup.com).

\section{Call for peer reviewers}

Clinical Evidence also needs to recruit a number of new peer reviewers specifically with an interest in the clinical areas stated above, and also others related to general practice. Peer reviewers are health care professionals or epidemiologists with experience in evidence based medicine. As a peer reviewer you would be asked for your views on the clinical relevance, validity, and accessibility of specific topics within the journal, and their usefulness to the intended audience (international generalists and health care professionals, possibly with limited statistical knowledge). Topics are usually 2000-3000 words in length and we would ask you to review between 2-5 topics per year. The peer review process takes place throughout the year, and our turnaround time for each review is ideally 10-14 days.

If you are interested in becoming a peer reviewer for Clinical Evidence, please complete the peer review questionnaire at www.clinicalevidence.com or contact Claire Folkes (cfolkes@bmigroup.com). 